\title{
Traumatic aniridia and aphakia with scleral buckling: a case report
}

\author{
CHAKKO PUTHENPURAYIL THOMMY \\ From the Guinness Ophthalmic Unit, Ahmadu Bello University Teaching Hospital, \\ Kaduna, Nigeria
}

SUMMARY A case is reported of a young man in whom blunt injury caused a horizontal corneal tear superiorly. Aniridia, aphakia, cyclodialysis with angle recession, minimal hyphaema, vitreous haemorrhage, choroidal rupture and striae, and scleral buckling resulted. Vision improved to $6 / 12+$.

Aniridia from blunt or perforating injuries usually occurs in association with severe damage to the eye. ${ }^{1}$ Aniridia with aphakia resulting from such injuries is rare. To find cyclodialysis, angle recession, choroidal ruptures and striae, and scleral buckling associated with aniridia and aphakia with an intact vitreous face and minimal hyphaema must be unique. This case is reported because of these rare findings. Return of visual function in this case is also remarkable.

$\mathrm{Malec}^{2}$ reported a case of aniridia and aphakia. Romem and Singer ${ }^{3}$ and Trobe and Keeney ${ }^{4}$ reported cases of traumatic aniridia with subsequent return to good visual function. Aviel and Avisar, ${ }^{5}$ Argento and Sampaolesi, ${ }^{6}$ and Bartkowska-orlowska and Orlowski ${ }^{7}$ reported cases of traumatic cyclodialysis and angle recession. Earlier reports of aniridia and aphakia were summarised by Duke-Elder and Macfaul. ${ }^{1}$

\section{Case report}

A 30-year-old male, a bank attendant, was seen in the emergency outpatient clinic of the Guinness Ophthalmic Unit, Ahmadu Bello University Hospital, on the evening of 3 November 1978. About 2 hours previously he had sustained a blow with a clenched fist in his right eye. He then attended a private clinic, where the eye was cleaned and all 'leaking material' removed.

His visual acuity in the right eye was hand movements and in the left eye 6/6. There were no marks of violence nor any contusion or abrasion around the right eye. The conjunctiva was slightly congested. The cornea was clear, but there was a horizontal serrated wound superiorly from 10.30 to 2.00

Correspondence to Dr Chakko P. Thommy. o'clock position, resembling a too corneal, small incision for a cataract extraction. The anterior chamber was formed but rather shallow. A small hyphaema of about $2 \mathrm{~mm}$ was present. No iris was visible. The ciliary processes were clearly seen all round except inferiorly because of the hyphaema. The lens was absent. The vitreous face was intact and showed a streak of blood. The fundus was hazy, and details could not be made out. Slit-lamp examination confirmed these findings. A search was made in vain for the iris and the lens in the anterior chamber and under the conjunctiva.

The corneal wound was sutured under general anaesthesia. Again a search was made without avail to see if the iris and/or lens could be located under the conjunctiva or in the anterior chamber. The vitreous chamber was full of blood. Gonioscopically the angle appeared surprisingly clear except for a few small dots of blood and the hyphaema spread out in the inferior quadrant. The line of attachment of iris from where it was torn off could be made out. The eye was hypotonic, and so air was injected to bring up the intraocular pressure to optimum. Subconjunctival depot methyl prednisolone $20 \mathrm{mg}$ and gentamicin $20 \mathrm{mg}$ were given. Atropine drops and antibiotic eye ointment were applied and the eye was bandaged.

Postoperatively the patient was on systemic antibiotics for 7 days. Systemic corticosteroids were given from the first postoperative day in a short course on a gradually reducing regimen and were discontinued at the end of 2 weeks. On the first postoperative day the hyphaema had increased to about $3 \mathrm{~mm}$, which cleared gradually. On the 9 th day the intraocular pressure was raised $(25 \mathrm{mmHg}$ applanation) and he was given acetazolamide $250 \mathrm{mg}$ twice a day for 4 days followed by once a day for another 4 days, when the tension was found to have 
returned to normal. Otherwise the postoperative period was uneventful and he was discharged on the 13th day to attend the outpatient clinic once a week.

When the hyphaema was absorbed an area of cyclodialysis between 5 and 8 o'clock position was detected. At the end of 3 weeks the vitreous was clearing up, and by the fourth week the fundus could be seen by the indirect ophthalmoscope. The disc and macula were normal. A linear raised ridge was found running in the lower half, anterior to the equator and parallel to it, almost like the appearance of an encircling band in retinal detachment surgery, in continuation of an area of choroidal rupture from 9.30 to 8 o'clock and ending in choroidal striae superonasally. In the periphery between 9 and 8.30 o'clock 3 blood dots were noted. No iris or lens could be located in the fundus.

Gonioscopy at this time did not reveal the iris either. The iris was torn cleanly and totally from all around. The angle was open. The inferior quadrant showed pigmentation on the trabeculum and the angle recessed in the area of cyclodialysis. The applanation pressure was $10 \mathrm{mmHg}$ in the right eye and $12 \mathrm{mmHg}$ in the left eye.

The following were the findings in the right eye: superior horizontal serrated corneal tear; aniridia; aphakia; small hyphaema; vitreous haemorrhage; cyclodialysis and angle recession; choroidal rupture and choroidal tear; scleral buckling.

At 2 months the eye condition remained essentially the same. The anterior segment did not show any further changes. The traumatic scleral buckling remained the same. The choroidal tears had become whitish, exposing the sclera and with pigment round them. The choroidal striae had also progressed to a similar pattern, and all these have a concentric appearance parallel with the equator, which is almost complete with only small discontinuity in between.

The right eye has remained quiet for the last 13 months. The visual acuity was counting fingers at $1 \mathrm{~m}$, which improved to $\mathrm{RE}+7.50$ sphere +2.75 cylinder $155^{\circ}=6 / 12+$. The intraocular pressure was $15 \mathrm{mmHg}$. The vitreous face remained intact. Gonioscopy did not show any changes except that the angle recession was seen to be minimal. No scleral buckling could be made out in the fundus now. The atrophic areas of choroidal damage were the only signs of the injury in the fundus at this time. The left eye was normal, with a visual acuity of $6 / 5$.

\section{Discussion}

This case is interesting in many ways. After a heavy blow with a clenched fist the eye showed very little reaction (minimal conjunctival redness, an almost clear cornea even with a rupture superiorly, a formed though shallow anterior chamber, and minimal hyphaema). A superior horizontal corneal tear is also surprising, though the cornea must have torn at the site of maximum impact. ${ }^{8}$ Almost invariably a total hyphaema accompanies every case of traumatic aniridia. ${ }^{1}$ In this case, however, the hyphaema was slight. Except for the limited cyclodialysis there were no changes in the angle of the anterior chamber, which might explain this minimal hyphaema. Aniridia and aphakia occurred simultaneously, which is extremely rare, and it is more surprising because the lens had been extruded without disturbing the vitreous face in a young person.

Forces generated inside the globe at the moment of impact detached the iris completely, the returning wave of pressure from the posterior scleral wall forcing the vitreous against the lens and totally dislocating it. Both lens and iris were carried through the torn cornea, which 'leaking material' had been cleaned at the first place of attendance and so was lost to observation. ${ }^{1}$ The choroidal rupture may be explained by mechanical factors, the globe being pushed against the bony orbit.

The scleral buckling observed in this eye has not been reported previously but can be explained by the same mechanical factor of the globe being forcibly pushed against the hard bony orbit. That this buckling was prominent in the inferior half is because greater force was exerted there by the fist, the inferior and lateral aspects of the orbit not being obstructed by the superior orbital rim and the nose. This scleral buckling smoothed out and the sclera regained its normal contour after about 9 months, which is also remarkable.

The transient rise of intraocular pressure could be due to traumatic inflammation in the trabecular area. The vitreous haemorrhage cleared rather rapidly, perhaps because of the early institution of corticosteroid therapy. The absence of any damage to the posterior pole of the retina, including the macula, helped the return of good vision.

Recovery after severe ocular trauma and regaining useful to excellent vision is increasing in frequency after the more recent practice of detailed evaluation of the injury ${ }^{6}{ }^{7}$ and meticulous surgical management of these cases. ${ }^{8-13}$ Perhaps perfect coaptation of the various wound edges, thus restoring the normal anatomy of the eyeball, and reformation of the anterior chamber with air or balanced salt solution to restore normal intraocular pressure, are the 2 most important aspects in the management of severe ocular trauma after surgical cleanliness and combating infection. 


\section{References}

${ }^{1}$ Duke-Elder S, Macfaul PA. Injuries. In: Duke-Elder S, ed. System of Ophthalmology. London: Kimpton, 1972: 14 (1): 108-14, 144-8, 151-5.

${ }^{2}$ Malec J. An interesting case of ocular injury. Cesk Oftalmol 1978; 34: 331-2.

${ }^{3}$ Romem M, Singer L. Traumatic aniridia. Br J Ophthalmol $1973 ; 57: 613-4$.

'Trobe JD, Keeney HA. Traumatic aniridia. Am J Ophthalmol 1974; 78: 1006- 8 .

${ }^{5}$ Aviel E, Avisar R. Traumatic cyclodialysis-a case report. Br J Ophthalmol 1976; 60: 748-9.

Argento C, Sampaolesi R. Traumatic lesions of the anterior chamber angle and ocular tension. Arch Oftal $B$ Aires 1976; 51 : 103-12.
'Bartkowska-Orlowska M, Orlowski WJ. Importance of evaluation of the irido-corneal angle after injury ii. Post traumatic recession of the angle. Klin Oczna 1976; 46: 193-7. ${ }^{8}$ Cherry PMH. Indirect traumatic rupture of the globe. Arch Ophthalmol 1978; 88: 498-507.

${ }^{9}$ Ealing E. Perforating injuries of the eye. Br J Ophthalmol $1976 ; 60$ : 732-6.

${ }^{10}$ Adhikary HP, Taylor P, Fitzmaurice DJ. Prognosis of perforating eye injury. Br J Ophthalmol 1976; 60: 737-9.

"Faulborn J. Microsurgical reconstruction of severely injured eyes. Aktuel Traumatol 1977; 7: 81-4.

${ }^{12}$ Kiessig H, Steinbach PD. Course and prognosis of penetrating ocular injuries in the adults. Aktuel Traumatol 1976; 6: 15-23.

${ }^{13}$ Neubauer $\mathrm{H}$. Management of trauma of the anterior segment. Trans Ophthalmol Soc UK 1978; 98: 30-3. 